\title{
Ultraviolet B induced bioactive changes of enzymatic and non-enzymatic antioxidants and lipids in Trigonella foenum-graecum L. (Fenugreek)
}

\author{
Abin Sebastian, Rima Kumari, Boda Ravi Kiran and Majeti Narasimha Vara Prasad*
}

\begin{abstract}
Ultraviolet radiation (UV) altered plant metabolism. Hence Trigonella foenum-graecum L. (Fenugreek) exposed to UV-B radiation for studying the bioactive changes that may be useful in captive farming. UV-B treatment altered plant growth, and extent of alterations depended on the duration of radiation treatment. Photosynthetic pigments such as chlorophyll and carotenoids decreased after radiation exposure. But bioactive components such as anthocyanin, flavonoids, and phenolics increased after UV-B treatment. Phenylalanine lyase enzyme activity and peroxidase activity also increased with $4.0 \mathrm{hr}$ UV-B exposure even though $8.0 \mathrm{hr}$ exposure decreased the activity of these enzymes. Total lipid content of the plants increased after UV-B exposure. Changes in aromatic oil composition observed due to UV-B exposure, and the changes pointed shifting of plant metabolism towards the synthesis of short chain fatty acid contain lipids and non-enzymatic antioxidants.
\end{abstract}

Keywords: ultraviolet light, pigments, antioxidants, lipids, aromatic oil

Department of Plant Sciences, University of Hyderabad, Hyderabad, Telangana, India, 500046.

*Corresponding author: M.N.V. Prasad E-mail:mnvsl@uohyd.ac.in

DOI: $10.2478 /$ ebtj-2018-0010

\section{Introduction}

Ultraviolet B (UV-B) radiation had deleterious effects on plants (1). These changes included the production of reactive oxygen species (ROS), serious damage at the DNA level, a decrease of water use efficiency rate, impair photosynthesis and decrease in biomass productivity of plants $(1,2)$. On the other hand, synthesis of plant secondary metabolites stimulated at low level exposure to UV-B, and played a regulatory role in antioxidant defense mechanism (3). These compounds include phenols, flavonoids, anthocyanin, alkaloids and terpenoids (3). Pharmaceutical and culinary properties of medicinal and aromatic plants associated with these plant health sensory secondary compounds. Therefore, even though UV-B triggers the secondary metabolic pathway, it may serve as a significant stimulator for plant antioxidant activity. Due to this concern, UV-B is proven as beneficial aspect in case of medicinal and aromatic plants $(4,5)$, if supplemented below sub-lethal dose (6).

Secondary metabolites derived from the intermediates of primary housekeeping metabolism and the compounds are not important for plant growth. But these compounds acted as components of plant defense, chemical messengers, and transcription regulators (3). Synthesis of phenolics and flavonoids increased in response to UV-B radiation for the screening of the radiation and oxidative stress via antioxidant effects. (7). Thus the defensive mechanism operates during UV-B stress had beneficial effects that improved culinary and medicinal qualities of spices and medicinal plants. Evidently, ultraviolet radiation resulted in an increment of antioxidants such as tocopherol, ascorbic acid, and flavonoids $(8,9)$.

Phenolics had health promotive activities in human including prevention of cancer and oxidative stress associated disorders $(10,11)$. Most of the studies of the UV-B effect on plants showed an increase of phenolics (3). These compounds mitigated the deleteri- 

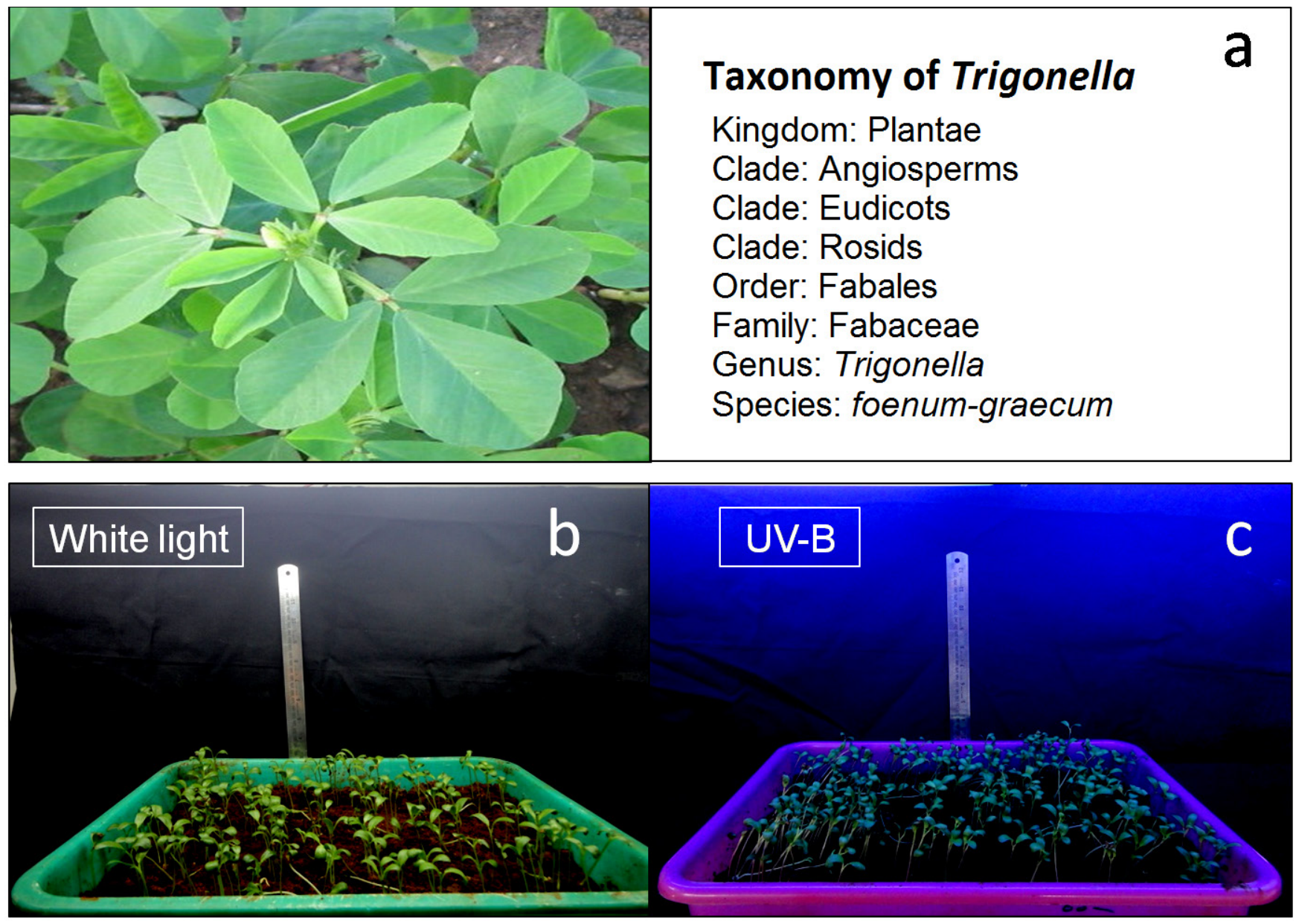

Figure 1. Experimental plant and UV-B light exposure: a. Trigonella plants; b. Plants under white light; c. Plants under UV-B light.

ous effects UV-B induced oxidative stress (12). Sweet flag and blueberries responded to UV-B radiation with an increment in antioxidant activity through an increase in the content of phenolics $(12,13)$. Phenolics absorbed ultraviolet radiation between 270 and $290 \mathrm{~nm}$, and therefore these compounds called as UV screening agents. Flavonoids rapidly induced by UV-B exposure. This response was directly linked to both increases in activity of enzymes participate in flavonoid biosynthesis. One of the well studied enzyme response during UV-B radiation was phenylalanine ammonia lyase (14). Transcription factors involved in synthesis and channeling of flavonoids also responded to UV-B radiation with an increase of flavonoids in the cell (14).

UV-B supplementation in a controlled manner increased the aromatic oil content of the plants (9). An increase of essential oil and changes in the ingredients of volatile oils observed in Ocimum basilicum, Mentha piperata, Glycyrrhiza uralensis $(15,16,17)$.The chemical changes in the essential oil composition found to decrease the toxic chemicals in medicinal plants. For example, b- asarone which is a potentially toxic constituent an important Indian medicinal plant Acorus calamus decreased after UV-B supplementation (10). Thus, UV-B treatment poses beneficial changes on metabolism that improve medicinal as well as aromatic qualities. Trigonella foenum-graecum $\mathrm{L}$. (Methi) is an annual, leguminous plant in the family Fabaceae.
The fresh leaves and seeds of the plant used as a green vegetable and spice respectively. Leaves consist of three oblong to obovate leaflets and are aromatic. Apart from the aroma, the plants are a good source of calcium, phosphorous, iron, and polyphenolics with antioxidant properties $(11,18)$. The major medicinal properties of this plant are hypoglycemic, hypocholesterolemic, anti-lipidemia, hepatoprotective, anti-inflammatory, anti-bacterial, anti-fungal, anti-ulcer, anti-lithigenic and anti-carcinogenic (18). Studies also demonstrated the medicinal properties of Trigonella seeds as a carminative, gastric stimulant, antidiabetic and galactogogue (lactation-inducer) (19). Leaf of this plant is known for its appetizing fragrance and is a basic ingredient in many Indian culinary preparations. It is assumed that UV-B treatment increase medicinal and aromatic ingredients in the plants. Therefore, the present study intended to evaluate UV-B induced responses in Trigonella for captive farming aim towards enhancement in medicinal and aromatic values of the plant.

\section{Materials and Methods \\ Plant growth}

Trigonella seeds sterilized in $5.0 \%$ hydrogen peroxide for 15.0 min and thereafter cleaned using double distilled water. Germination of seeds performed at a light intensity of $50.0 \pm 5.0$ 
$\mu \mathrm{mol}$ photons $\mathrm{m}^{-2} \mathrm{~s}^{-1}$ inside a pot containing soil. The soil airdried and sieved $(3 \mathrm{~mm}$ ) for removing debris of root and tiny particles of stones prior to pot culture. Seedlings of 21.0 days of growth selected for U VB supplementation.

\section{UV-B treatments}

UV-B treatments performed with UV-B light having an intensity of $3.0 \mathrm{KJ} / \mathrm{Sec}$ (Fig. 1). Daily UV-B treatment performed on two separate groups of plants for $4.0 \mathrm{hrs}$ and $8.0 \mathrm{hrs}$ respectively along with white light (14.0 hrs). Control plants maintained under $14.0 \mathrm{hrs}$ of white light exposure daily. White light intensity $\left(700.0 \pm 5.0 \mu \mathrm{mol}\right.$ photons $\left.\mathrm{m}^{-2} \mathrm{~s}^{-1}\right)$, photoperiod $(18.0 \mathrm{hrs}$ light and $6.0 \mathrm{hrs}$ dark), temperature $\left(25.0 \pm 2{ }^{\circ} \mathrm{C}\right)$ and water supply (20.0 mL per day) and relative humidity $(50.0 \pm 10.0 \%)$ maintained all the 7.0 days of the experimental tenure.

\section{Estimation of pigments}

Chlorophyll and carotenoids quantified using leaf extract in acetone: dimethyl sulphoxide (50:50). The optical density of leaf extract measured at 470.0, 646.0 and $663.0 \mathrm{~nm}$ and content of pigments estimated with the following formulae (20). Total chlorophyll = $20.2($ A646 $)+8.02($ A663 $)$; Chlorophyll a $=12.21$ (A663) - 2.81 (A646); Chlorophyll b = 20.13 (A646) 5.03 (A663); Carotenoids $=(1000 \mathrm{~A} 470-3.27[\mathrm{chl} \mathrm{a}]-104[\mathrm{chl}$ b])/227. Anthocyanin quantified from methanol/HCl/water (90:1:1) extract of leaf powder. The absorbance of the extracts read at 530 (A530) and 657(A657). Amount of anthocyanin calculated using formulae A530 - A 657 (21). Amount of pigments expressed in absorbance per gram fresh weight of leaf tissue.

\section{Estimation of phenolics}

Total phenolics estimated from the methanol extract of dried leaf powder. Leaf powder (1.0g) extracted with $10.0 \mathrm{ml}$ methanol. To the extract, $5.0 \mathrm{ml}$ of $0.1 \%$ Folin Ciocalteu reagent and $4.0 \mathrm{ml}$ of $1.0 \mathrm{M}$ sodium carbonate added. The reaction mixture incubated for $15.0 \mathrm{~min}$. The amount of phenolics determined after measuring absorbance at $765.0 \mathrm{~nm}$ (22). Gallic acid dissolved in $50.0 \%$ methanol used to make a standard graph, and the result represented as the equivalent of gallic acid.

\section{Analysis of flavanoids}

A colorimetric assay with aluminum chloride performed for the estimation of total flavonoids in plants (23). Leaves dried and powdered. Leaf powder (1.0 g) extracted using $10.0 \mathrm{ml}$ of methanol in an orbital shaker $(100.0 \mathrm{rpm})$ for $12.0 \mathrm{hrs}$. The clear extract obtained after centrifugation at $10000.0 \mathrm{~g}$. Reaction mixture comprised $3.0 \mathrm{ml}$ extract, $0.3 \mathrm{ml} 5.0 \% \mathrm{NaNO}_{2}$ and $0.3 \mathrm{ml} 10.0 \% \mathrm{AlCl}_{3}$. The mixture incubated for $6.0 \mathrm{~min}$ and after that mixed with $2.0 \mathrm{ml}$ of $1 \mathrm{M} \mathrm{NaOH}$. The final of the reaction mixture made to $10.0 \mathrm{ml}$ using double distilled water. The reaction mixture very well mixed and the optical density measured at $510 \mathrm{~nm}$. Quercetin used to make a standard graph, and the amount of flavonoids expressed in terms of quercetin $g$ equivalents mg per $\mathrm{g}$ dried plant tissue.

\section{Activity of total antioxidants}

The phosphomolybdenum method used to determine total antioxidants (24). The reagent prepared by mixing 0.6 M sulphuric acid, $28.0 \mathrm{mM}$ sodium phosphate and $4.0 \mathrm{mM}$ ammonium molybdate. Methanol extract $(100.0 \mu \mathrm{l})$ prepared from $10.0 \mathrm{~g}$ dried leaf powder in $10.0 \mathrm{ml}$ methanol mixed with $1.0 \mathrm{ml}$ of phosphomolybdenum reagent and the vials kept in boiling water bath for $90.0 \mathrm{~min}$. The vials canned and incubated in a water bath at $95^{\circ} \mathrm{C}$ for $90.0 \mathrm{~min}$. The optical density of the reaction mixture read at $695.0 \mathrm{~nm}$ after cooling. Ascorbic acid used for preparing standard graph and the result expressed in $\mu \mathrm{g}$ of ascorbic acid equivalents present in per dry tissue.

\section{Peroxidase assay}

Peroxidase assay performed from enzyme homogenate prepared using of $50.0 \mathrm{mM} \mathrm{L}^{-1}$ potassium phosphate buffer $(\mathrm{pH}$ 7.0 ). Leaves $(1.0 \mathrm{~g})$ powdered and homogenized with phosphate buffer. The homogenate centrifuged at $10000.0 \mathrm{~g}$ for $20.0 \mathrm{~min}$ at a temperature of $4.0^{\circ} \mathrm{C}$. The supernatant containing enzymes used for assay after quantification of protein (25). Assay of peroxidase performed using hydrogen peroxide and O-diasidine (26). The reaction carried out after the addition of extract containing enzyme at $25.0^{\circ} \mathrm{C}$ for $3.0 \mathrm{~min}$. The increase of optical absorbance at $420.0 \mathrm{~nm}$ per minute used to calculate the activity of the enzyme.

\section{Assay of phenylalanine ammonia-lyase}

The enzyme extracted from $300.0 \mathrm{~g}$ leaf tissues using $6.5 \mathrm{ml}$ of $50.0 \mathrm{mM}$ Tris- $\mathrm{HCl}$ buffer ( $\mathrm{pH} 8.8$ ) containing $15.0 \mathrm{mM}$ of $ß$-mercaptoethanol (27). The resulting homogenate centrifuged at $10000.0 \mathrm{~g}$ for $30.0 \mathrm{~min}$. The amount of protein in the supernatant assayed by the method of Lowry et al. 1951(25). The activity of the enzyme calculated on the basis of formation of cinnamic acid. The reaction mixture contained $1.0 \mathrm{ml}$ extraction buffer, $0.5 \mathrm{ml}$ of $10.0 \mathrm{mM} \mathrm{L}$-phenylalanine, $0.4 \mathrm{ml}$ of Milli Q water and $0.1 \mathrm{ml}$ of enzyme extract. The reaction carried out at $37^{\circ} \mathrm{C}$ for $1 \mathrm{~h}$ and terminated using $0.5 \mathrm{ml}$ of $6.0 \mathrm{M}$ $\mathrm{HCl}$.The absorbance of the reaction mixture recorded at 290.0 $\mathrm{nm}$. A unit of the enzyme activity defined as $1.0 \mu \mathrm{mol}$ of cinnamic acid formed in a minute.

\section{Quantification of total lipids}

Total lipids in the dried leaf tissues initially extracted using chloroform and methanol mixture (50:50) and homogenized for 30.0 s. Subsequently, chloroform added for second and third times with a homogenization period of the 30s. After that, the extract mixed with water. The organic and aqueous phases separated using a clinical centrifuge run at $3000.0 \mathrm{rpm}$. The lower organic solvents phase was taken out with the help of a syringe and filtered using Whatman No.1 filter paper. Gravimetric quantitative estimation of lipids performed after the removal of the chloroform using a rotary vacuum evaporator.

\section{Aromatic oil composition}

Leaves dried using hot air oven at $40{ }^{\circ} \mathrm{C}$. The samples powdered, and $5.0 \mathrm{~g}$ of powder extracted with propanol using a 

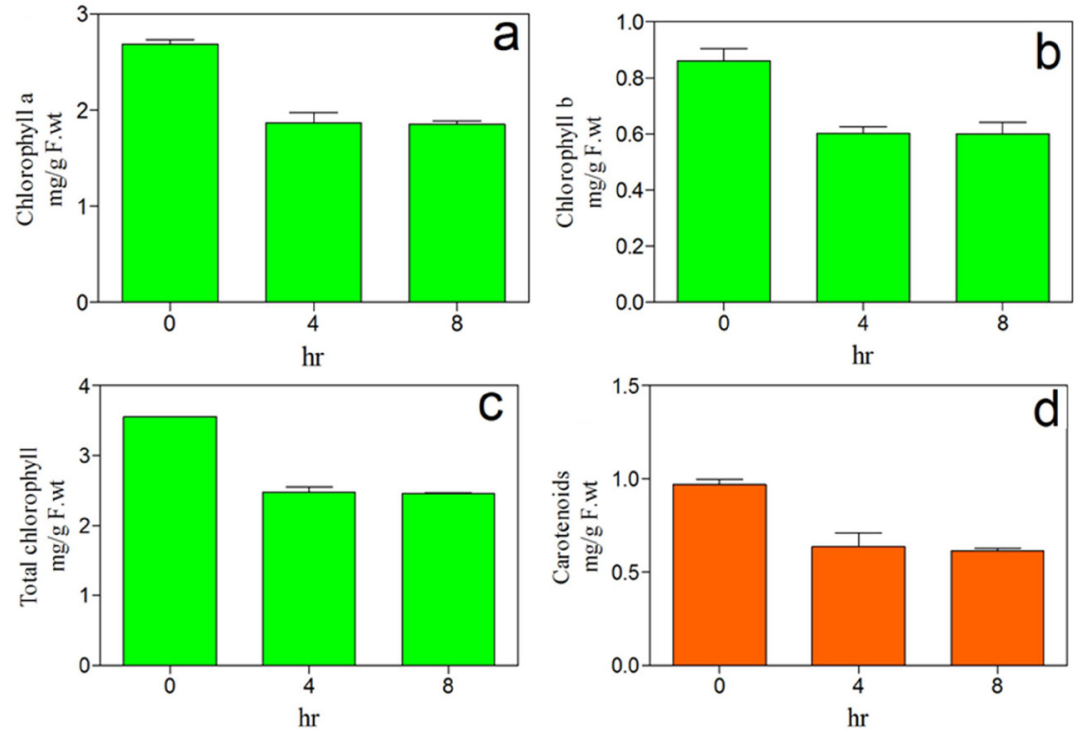

Figure 2. Effect of UV -B exposure on photosynthetic pigment contents of Trigonella: $a$. Chlorophyll a; b. Chlorophyll b; c. Total chlorophyll; d. Carotenoids.

soxhlet apparatus for $4.0 \mathrm{hr}$ at $100{ }^{\circ} \mathrm{C}$ and the volume made to $1.0 \mathrm{ml}$ using a rotary evaporator for GC-MS analysis. Gas chromatography coupled to mass spectrometry performed using DB-1HT capillary column and after that mass of the components (Agilent 7890A) (28). Sample (1.0 $\mu$ l) injected manually for electron ionization $(70.0 \mathrm{eV})$. The initial oven temperature maintained at $70{ }^{\circ} \mathrm{C}$ for $5.0 \mathrm{~min}$, and the temperature increased to $290{ }^{\circ} \mathrm{C}$ at a rate of $5{ }^{\circ} \mathrm{C}$ per minute. Helium used as carrier gas, and the flow rate was $1.5 \mathrm{ml}$ per minute. The temperature of mass spectrometer injector and transfer line adjusted to $250{ }^{\circ} \mathrm{C}$ and $225{ }^{\circ} \mathrm{C}$ respectively. The chemical identity of the compounds screened via comparison of the mass spectra with the NIST14 library (29).

\section{Results}

\section{Photosynthetic pigments}

UV-B light treatment caused a decrease of photosynthetic pigments in Trigonella (Fig. 2). Maximum percentage decrease of pigments take part in photosynthesis such as chlorophyll a, chlorophyll b, total chlorophyll, and carotenoids were 31.0, $30.0,30.0$ and $36.0 \%$ respectively upon UV-B treatment (Fig. 2a-d).

\section{Bioactive compounds}

Bioactive compounds that protect plants from oxidative stress increased upon UV-B exposure (Fig. 3). Anthocyanin which detoxifies reactive oxygen species increased with UV-B treat-
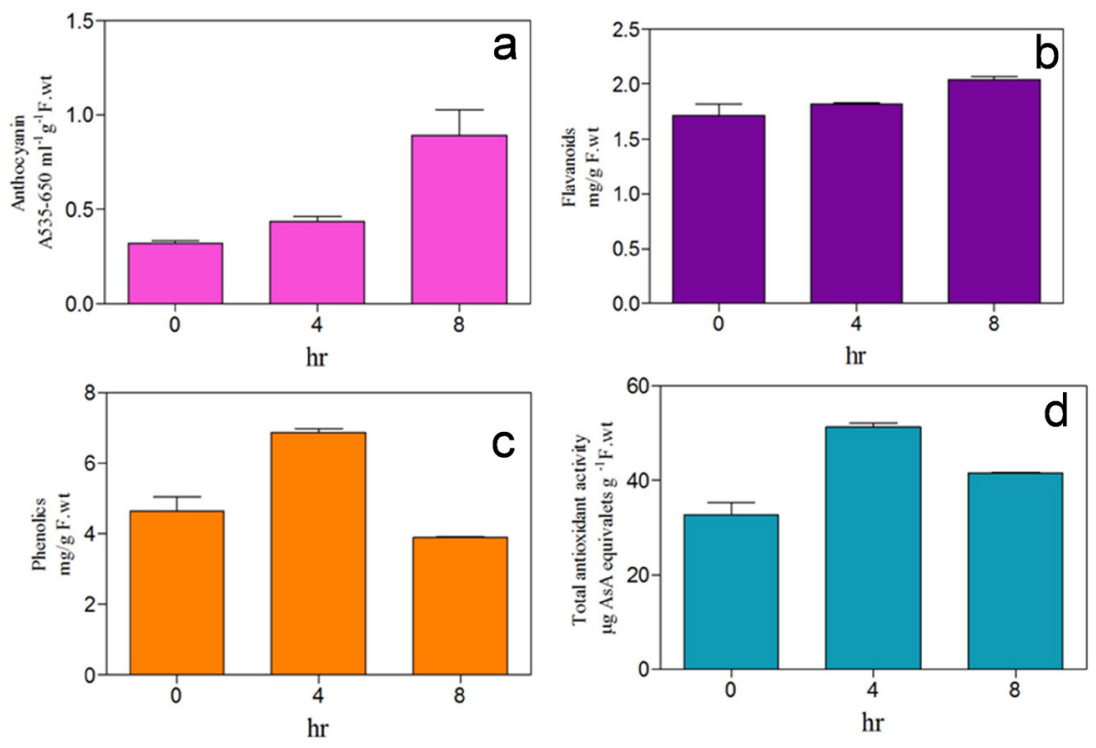

Figure 3. UV- B exposure related changes of bioactive compounds in herbal extract of Trigonella: a. Anthocyanin; b. Flavanoids; c. Phenolics; d. Total antioxidant activity. 

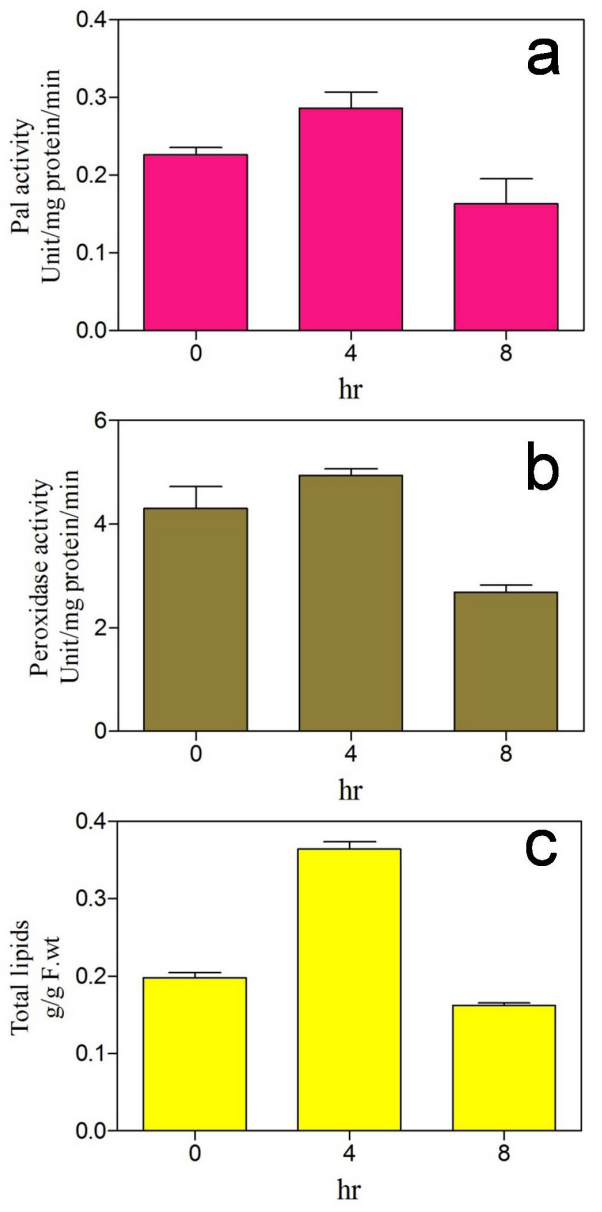

Figure 4. Effect of UV Antioxidant enzyme activies (a. Phenylalanine lyase; b. Guiacol peroxidase) and total lipid content of test plants up on UV- B exposure.

ment in Trigonella ( 2 fold) (Fig. 3a). Similarly flavanoids content found to increase up to $18.0 \%$ (Fig. 3b). It is noteworthy that both anthocyanin and flavonoids content increased linearly with duration of UV-B exposure among test plants. Trigonella produced $48.0 \%$ more phenolics after $4.0 \mathrm{hr}$ UV-B radiation even though $8.0 \mathrm{hr}$ UV-B treatments caused $15.0 \%$ decrease in phenolics content (Fig. 3c). Total antioxidant capacity of plants represented in terms of ascorbic acid equivalents increased in Trigonella up to 56.0 and $26.0 \%$ respectively after 4.0 and 8.0 hrs of UV-B treatments (Fig. 3d).

\section{Peroxidase and phenylalanine lyase activity}

The activity of phenylalanine lyase increased $26.0 \%$ increase after $4.0 \mathrm{hr}$ UV-B exposure even though $8.0 \mathrm{hr}$ exposure decreased the activity of this enzyme (Fig. 4a). Long-term UV-B exposure decreased peroxidase activity (up to $37.0 \%$ ) in Trigonella plant whereas short-term UV-B exposure enhanced peroxidase activity up to $14.0 \%$ (Fig. $4 \mathrm{~b}$ ).

\section{Total lipid content}

Total lipid is an indicator of oil content because oils are triacylglycerides. It has been found out that UV-B exposure enhances lipid content of both the test plants even though long-term exposure to UV-B decreased lipid content (Fig. 4c). Lipid content increased upon $4 \mathrm{hr}$ UV-B treatments up to $83.0 \%$ and the lipid content decreased $18.0 \%$ during 8.0 hr UV-B treatment.

\section{Changes in composition of aromatic oils}

GC-MS analysis revealed changes in 10 compounds in the aromatic oil of Trigonella after UV-B treatment (Fig. 5, Table 1). The compounds decreased after UV-B treatment are nonadecane, 2-methyl (15.255\%), Phytol (11.534\%), and nonacos-1-ene $(8.697 \%)$. The compounds that increased during UV-B exposure are 2-Pentadecanone,6,10,14-trimethyl (9.7588\%), n-Tetracosanol-1 (4.6159\%), 11-methyldodecanol (2.2113\%), 2-dodecanol,2-methyl (1.8447\%), octadecane,2-methyl (1.8169\%), Eicosane,2-methyl (1.7377\%), and pentadecanoic acid 14-methyl-methyl ester (1.5965\%).

\section{Discussion}

UV-B radiation resulted in operation of stress defense responses in the experimental plants. UV-B treatment increased chlo-

Table 1. UV B induced changes in chemical composition of Trigonella leaves

\begin{tabular}{|c|c|c|c|c|}
\hline Peak No. & R.T.(s) & Area\% & Control & Formula \\
\hline 98 & 1830.4 & -11.534 & Phytol & $\mathrm{C}_{20} \mathrm{H}_{40} \mathrm{O}$ \\
\hline 137 & 2226 & -15.255 & Nonadecane,2-methyl & $\mathrm{C}_{20} \mathrm{H}_{42}$ \\
\hline 165 & 2549.8 & -8.697 & Nonacos-1-ene & $\mathrm{C}_{29} \mathrm{H}_{58}$ \\
\hline 99 & 1525.4 & +1.8477 & 2-Dodecanol,2-methyl & $\mathrm{C}_{13} \mathrm{H}_{28} \mathrm{O}$ \\
\hline 100 & 1534 & +9.7588 & 2- Pentadecanone,6,10,14-trimethyl & $\mathrm{C}_{18} \mathrm{H}_{36} \mathrm{O}$ \\
\hline 115 & 1626.2 & +1.5965 & Pentadecanoic acid,14-methyl-,methylester & $\mathrm{C}_{17} \mathrm{H}_{34} \mathrm{O}_{2}$ \\
\hline 143 & 1909.4 & +2.2113 & 11-methyldodecanol & $\mathrm{C}_{13} \mathrm{H}_{28} \mathrm{O}$ \\
\hline 170 & 2230.2 & +1.8169 & Octadecane,2-methyl & $\mathrm{C}_{19} \mathrm{H}_{40}$ \\
\hline 185 & 2564.4 & +4.6159 & n-Tetracosanol-1 & $\mathrm{C}_{24} \mathrm{H}_{50} \mathrm{O}$ \\
\hline 193 & 2720.8 & +1.7377 & Eicosane,2-methyl & $\mathrm{C}_{21} \mathrm{H}_{44}$ \\
\hline
\end{tabular}




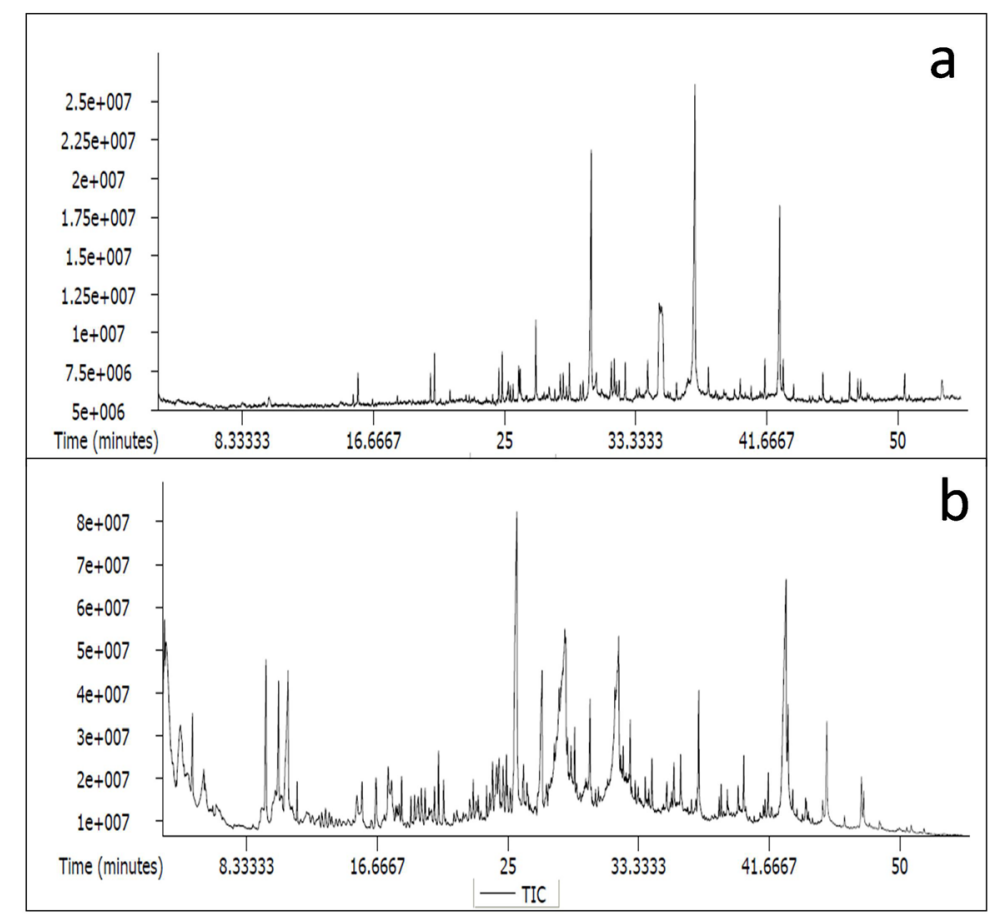

Figure 5. GC-MS spectra revealing effect of UV- B radiation on essential oil composition of Trigonella. a. Control plants; b. UV- B exposed plants $(4.0 \mathrm{hr})$.

rophyll and carotenoid content in plants, and the effect was dependent on genetic makeup, growth stage of the plant, and duration of exposure (30). But plants adapt to highlight energy caused photo-oxidative stress through the diminution of chlorophyll (31). These changes helped to decrease the impact of high energy radiation by lowering of light energy harvest (32). Carotenes help to dissipative excess light energy through operation of non-photochemical quenching (30). Hence the decrease of both chlorophyll and carotenoids content in Trigonella upon UV-B exposure indicated that these plants subjected to photooxidative stress (31). The analysis of bioactive compounds and activities of antioxidant enzymes indicated photo-oxidative stress was more after $8.0 \mathrm{hr}$ UV-B exposure.

Synthesis of bioactive compounds enhanced during plant stress (33). Phenolics were the chief bioactive compounds responded to photooxidative stress (34). These compounds acted as antioxidants and scavenger of free radicals (35). Hence, the phenolics considered as idyllic for maintaining the cellular redox level during photooxidative stress. Studies also showed that phenolics quickly repair DNA damage during the attack of free radical anions through electron transfer reaction (36). Flavonoids such as anthocyanin are the class of phenolics that enabled photo-oxidative stress tolerance in plants (37). Activity phenylalanine lyase (PAL) mediates the coumaroyl CoA synthesis critical for the production of phenolic acids and flavonoids in plants (14). Therefore increase in phenolics content and activity of PAL enzyme enhanced stress tolerance during short-term UV-B exposure. This result confirmed with an increase in total antioxidant activity among these plants. It could be the senescence-related metabolite degradation which resulted in plants to produce more anthocyanin and flavonoids dur- ing $8.0 \mathrm{hr}$ UV-B exposure. The low activity of PAL and peroxidase among plants subjected to $8.0 \mathrm{hr}$ UV-B treatment was the result of vulnerability to photooxidative stress. But the higher peroxidase activity helped plants to avoid severe photo-oxidative stress during $4.0 \mathrm{hr}$ UV-B exposure.

Essential oils production from aromatic plants such as Trigonella gained attention because of antioxidants capacity due to biologically active compounds in these oils (3). Primary metabolism shifts towards the synthesis of lipids when the plant experiences UV-B stress $(3,38)$. These results adjoin to increase of lipid content after UV-B treatment. The increase of lipid content attributed as a consequence of diversion housekeeping metabolic pathways towards lipid synthesis (38). But 8.0 hr UV-B treatment created severe oxidative stress and resulted in lipid peroxidation in the present study. Hence, lipid content was less after $8.0 \mathrm{hr}$ UV-B exposure. There occurred changes in essential oil composition during UV-B exposure in plants. In the present study, aliphatic compounds such as phytol, nonadecane, 2-methyl, and nonacos-1-ene decreased during $4.0 \mathrm{hr}$ exposure to UV-B. This change indicated diversion of synthetic pathways such as that of chlorophyll towards lipids and antioxidants synthesis respectively (3). These findings confirmed with an increase of compounds such as 2-dodecanol 2-methyl, 2- Pentadecanone, 6, 10, 14-trimethyl, pentadecanoic acid, 14-methyl-methyl ester, 11-methyldodecanol, octadecane, 2-methyl, n-tetracosanol-1 and eicosane,2-methyl that belong to the class of lipids and antioxidants $(39,40)$. Thus, the findings in the present study well states towards stimulatory effects of $4.0 \mathrm{hr}$ UV-B radiation to synthesis of lipids, phenolics, volatile production, and changes in active constituents. The results supported with earlier studies with regard to contribution 
of UV-B radiation causing stimulation of volatile production and changes in composition of active constituents. For example, UV-B treatment changed components in essential oil, phenolics, and antioxidants in Coleus aromaticus (4). Chang et al. (2009) also reported the increase of eugenol and linalool in volatile oil of Ocimum basilicum (41). Afreen et al. (2005) reported the increase in glycyrrhizic acid (a triterpenoid saponin) in Glycyrrhiza uralensis at optimum UV -B treatment but high intensity resulting in decreased value (17).

In conclusion, UV-B stress acts positively on Trigonella seedlings. UV-B exposure leads more production of flavonoids including anthocyanin in Trigonella. The increase of total lipids is a clear-cut evidence for an increase of biologically active compounds, especially essential oils upon UV -B treatment. Hence controlled UV -B exposure in captive farming (greenhouse cultivation) for $4.0 \mathrm{hr}$ is a promising strategy for enhancing aromatic as well as active principles of Trigonella.

\section{Acknowledgments}

RK thankfully acknowledges postdoctoral fellowship (Dr. D. S. Kothari, the University Grant Commission (UGC), New Delhi, India. BRK is the recipient of Rajiv Gandhi National Fellowship (RGNF-UGC) for Disabilities (ID No. 201314-RGNF-2013-14D-OBC-AND-56604). Thanks are also due to UGC, New Delhi for funding research project "Precision stressing by UV-B radiation to improve the quality of Coriander and Trigonella, ref. F. No. 41-389/2012 to MNVP.

\section{Conflict of interest statement}

The authors declare there is no conflict of interest.

\section{References}

1. Frohnmeyer H, Staiger D. Ultraviolet-B radiation mediated responses in plants. Balancing damage and protection. Plant Physiol 2003; 133:1420-1428.

2. Tripathi R, Sarkar A, Rai SP, Agrawal SB. Supplemental ultraviolet-B and ozone, impact on antioxidants, proteome and genome of linseed (Linum usitatissimum L. cv Padmimi). Plant Biol 2010; doi: 10.1111/j. 1438-8677.2010.00323.x.

3. Kumari R, Prasad M.N.V. (2013) Medicinal Plant Active Compounds Produced by UV-B Exposure Sustainable Agriculture Reviews 12, 225-254. E. Lichtfouse (ed.) Springer International Publishing Switzerland. DOI 10.1007/978-3-319-16742-8_8.

4. Kumari R, Prasad M.N.V. (2014) Effect of UV-B pretreatment on essential oil components, health sensory secondary metabolites and antioxidant potential of Coleus aromaticus. International Journal of Biological \& Pharmaceutical Research 5(8): 675-688.

5. Kumari R, Prasad M.N.V, Agrawal S.B (2015) Growth and Defense Metabolism of Plants Exposed to Ultraviolet-B Radiation. Sustainable Agriculture Reviews 17, 263-305. E. Lichtfouse (ed.). Springer International Publishing Switzerland.DOI 10.1007/978-3-31916742-8_8

6. Kumari R, Agrawal SB, Singh S, Dubey NK. Supplemental ultraviolet- $B$ induced changes in essential oil composition and total phenolics of Acorus calamus L (Sweet flag). Ecotoxicol Environ Safety 2009; 72:2013-2019.

7. Rozema J, Bjorn LO, Bornman JF, Gaberscik A, Hader DP, Trost T, Germ M, Klisch M, Groiger A, Sinha RP, Lebert M, He YY, Buffoni Hall R, Bakker NVJ, de Staaji J, vande Meijkamp B. The role of UV-Bradiation in aquatic and terrestrial ecosystems-an experimental and functional analysis of the evolution of UV absorbing compound. J Photochem Photobiol B: Biol 2002; 66:2-12.

8. Higashio $H$, Hirokane $H$, Sato F, Tokuda S, Uragami A. Enhancement of functional compounds in Allium vegetables with UV radiation. Acta Hortic 2007; 744:357-361.

9. Kumari R, Agrawal SB. Comparative analysis of essential oil composition and oil containing glands in Ocimum sanctum L (Holy basil) under ambient and supplemental level of UV-B through gas chromatography-mass spectrometry (GC-MS) and Scanning electron microscopy (SEM). Acta Physiol Plant 2010; 33:1093-1110.

10. Holst B, Williamson G. A critical review of the bioavailability of glucosinolates and related compounds. Nat Prod Rep 2004; 21:425447.

11. Schreiner $M$, Krumbein A, Mewis I, Ulrichs $C$, Huyskens-Keil S. Short-term and moderate UV-B radiation effects on secondary plant metabolism in different organs of nasturtium (Tropaeolum majus L). Innov Food Sci Emerg Tech 2009; 10:93-96.

12. Jansen MAK, Hectors K, O'Brien N M, Guisez Y, Potters G. Plant stress and human health: do human consumers benefit from UV-B acclimated crops? Plant Sci 2008; 175:449-458.

13. Eichholz I, Huyskens-Keil S, Keller A, Ulrich D, Kroh LW, Rohn S. UV-B-induced changes of volatile metabolites and phenolic compounds in blueberries (Vaccinium corymbosum L). Food Chem 2011; 126:60-64.

14. Ravindran KC, Indrajith A, Balakrishnan V, Venkatesan K, Kulandaivelu G. Determination of defense mechanism in Phaseolus trilobus Ait seedlings treated under UV-B radiation. Af Crop Sci J 2010; 16:111-118.

15. Johnson CB, Kirby J, Naxakis G, Pearson S. Substantial UV-B-mediated induction of essential oils in sweet basil (Ocimum basilicum L). Phytochemistry 1999; 51(4):507-510.

16. Maffei M, Scannerini S. UV-B effect on photomorphogenesis and essential oil composition in peppermint (Mentha piperita L.). J Essent Oil Res 2000 ; 12: 529-529.

17. Afreen F, Zobayed SMA, Kozai T. Spectral quality and UV-B stress stimulate glycyrrhizin concentration of Glycyrrhiza uralensis in hydroponic and pot system. Plant Physiol Biochem 2005; 43:10741081.

18. Yadav UV, Baquer NZ. Pharmacological effects of Trigonella foenum-graecum L. in health and disease. Pharm Biol Pharm 2014; 52:243-54.

19. Kaviarasan S, Naik GH, Gangabhagirathic R, Anuradhaa CV, Priyadarsini KI. In vitro studies on antiradical and antioxidant activities of fenugreek (Trigonella foenum graecum) seeds. Food Chem 2007; 103:31-37.

20. Lichtenthaler HK, Wellburn AR. Determinations of total carotenoids and chlorophylls $a$ and $b$ of leaf extracts in different solvents. Biochem Soc Trans 1983; 11: 591 - 592.

21. Mancinelli A. Photoregulation of anthocyanin synthesis.VIII. Effects of light pre-treatments. Plant Physiol 1984; 75:447-453.

22. McDonald S, Prenzler PD, Autolovich M, Robards K. Phenolic content and antioxidant activity of olive extracts. Food Chem 2001; 73:73-84.

23. Kumar S, Kumar D, Manjusha, Saroha K, Singh N, Vashishta B. Antioxidant free radical scavenging potential of Citrullus colocynthis (L.) Schrad. Methanolic fruit extract. Acta Pharm 2008; 58:215-220.

24. Kumar R, Hemalatha S. In-vitro antioxidant activity of alcoholic leaf extract and subfractions of Alangium lamarckii Thwaites. J Chem Pharm Res 2011; 259-267.

25. Lowry OH, Rosebrough NJ, Farr AL, Randall RJ. Protein measurements with Folin-phenol reagent. J Biol Chem 1951; 193:265-275.

26. Padmaja M, Sravanthi M, Hemalatha KPJ. Evaluation of antioxidant activity of two indian medicinal plants. J Phytol 2011; 3(3):86-91.

27. Subbarao PV, Towers GHN. L-phenylalanine ammonia-lyase ( Ustilago hordei). In: Colowick SP and Kaplan NO [eds.] Meth Enzymol 1970; 581. 
28. Sun J, Wang X, Wang P, Li L, Qu W, Liang J. Antimicrobial, antioxidant and cytotoxic properties of essential oil from Dictamnus angustifolius. J Ethnopharmacol 1970; 159: 296-300.

29. Petropoulou Y, Kypariasis A, Nikolopoulous D, Menetus Y. Enhanced UV-B radiation alleviates the adverse effect of summer drought in two Mediterranean pines under field condition. Physiol Plant 1995; 94: 37-44.

30. Agrawal SB, Rathore D. Changes in oxidative stress defense system in wheat (Triticum aestivum $\mathrm{L}$ ) and mung bean (Vigna radiata $\mathrm{L}$ ) cultivars grown with and without mineral nutrients and irradiated by supplemental ultraviolet-B. Environ Exp Bot 2007; 59:21-33.

31. Greenberg BM, Wilson MI, Huang XD, Duxbury CL, Garhardt KE, Gensemerr W. The effects of ultraviolet- $B$ radiation on higher plants. In: Wang W, Gorsuch JW, Hughes JS [eds.], Plants for Environmental Studies, Boca Raton, CRC Press, Florida 1997; 1-36.

32. Sebastian A, Prasad M.N.V. Operative photo assimilation associated proteome modulations are critical for iron-dependent cadmium tolerance in Oryza sativa L. Protoplasma 2015; 252(5):13751386.

33. Agrawal SB, Singh S, Agrawal M. UV-B induced changes in gene expression and antioxidants in plants. Adv Bot Res 2009; 52:47-86.

34. Alothman $M$, Bhat $R$, Karim AA. Effects of radiation processing on phytochemicals and antioxidants in plant produce. Trends Food Sci Technol 2009; 20:201-212.
35. Dai J, Mumper RJ. Plant phenolics: extraction, analysis and their antioxidant and anticancer properties. Molecules 2010; 15:73137352.

36. Sperandio O, Fan BT, Zakrzewska K, Jia ZJ, Zheng RL, Panaye A, Doucet JP, Fassi NE. Theoretical study of fast repair of DNA damage by cistanoside $C$ and analogs: mechanism and docking. SAR QSAR Environ Res 2002; 13:243-260.

37. Atmani D, Chaher N, Atmani D, Boudaoud H, Debache N, Berboucha M. Flavonoids in human health: from structure to biological activity. Curr Nutr Food Sci 2009; 5: 225-237.

38. Dolzhenko Y, Bertea CM, Occhipinti A, Bossi S, Maffei ME. UV-B modulates the interplay between terpenoids and $f$ avonoids in peppermint ( Mentha piperita L). J Photochem Photobiol B Biol 2010; 100:67-75.

39. Ahmad P, Jaleel CA, Salem MA, Nabi G, Sharma S. Roles of enzymatic and nonenzymatic antioxidants in plants during abiotic stress. Crit Rev Biotechnol 2009; 30: 161-175.

40. Ohlrogge J, Browse J. Lipid Biosynthesis. The Plant Cell 1995; 7:957-970.

41. Chang X, Alderson PG, Wright CJ. Enhanced UV-B radiation alters basil (Ocimum basilicum $\mathrm{L}$.) growth and stimulates the synthesis of volatile oils. J Hort Forest 2009; 1: 27-31. 